\title{
Serrated polyps of the colon
}

\section{Aravind Sugumar and Frank A Sinicrope*}

Address: Division of Gastroenterology \& Hepatology and Division of Oncology, Mayo Clinic and Mayo College of Medicine, 200 First Street SW, Rochester, MN 55905, USA

*Corresponding author: Frank A Sinicrope (sinicrope.frank@mayo.edu)

FI000 Medicine Reports 2010, 2:89 (doi:10.3410/M2-89)

This is an open-access article distributed under the terms of the Creative Commons Attribution-Non Commercial License (http://creativecommons.org/licenses/by-nc/3.0/legalcode), which permits unrestricted use, distribution, and reproduction in any medium, provided the original work is properly cited. You may not use this work for commercial purposes.

The electronic version of this article is the complete one and can be found at: http://f1000.com/reports/m/2/89

\begin{abstract}
Until recently, colonic polyps were traditionally classified as either hyperplastic or adenomatous, and only the latter were believed to have the potential to progress to carcinoma. However, it is now appreciated that a subset of serrated polyps also appear to have malignant potential. Serrated polyps are a heterogeneous group of colon polyps that include hyperplastic polyps, sessile serrated adenomas (SSAs), traditional serrated adenomas, and mixed polyps. Insights into these polyps were derived, in part, from studies of patients with the hyperplastic polyposis syndrome. SSAs show a predilection for the right colon, have a distinct histology, and their molecular genetic profile has recently been linked to a pathway for colon tumorigenesis that is characterized by microsatellite instability. Based upon available evidence, it is recommended that patients with serrated adenomas undergo colonoscopic follow-up at the same frequency as for conventional adenomas. It is important that physicians are aware of serrated polyps, particularly serrated adenomas and their relationship to colon cancer, and their proper clinical management.
\end{abstract}

\section{Introduction and context}

Colon cancer is the fourth most common cause of cancer and is second only to lung cancer as a cause of cancer mortality in the United States [1]. Colon cancers are believed to develop from polyps and, until recently, the adenoma was considered the exclusive precursor lesion while hyperplastic polyps (HPPs) were deemed to have no malignant potential. However, accumulated evidence suggested that a subset of HPPs are associated with cancers. Such evidence includes the finding of hyperplastic tissue at the margin of adenomas and the association of larger HPPs, particularly in the right colon, with carcinoma [2-4]. In 1990, Longacre and Fenoglio-Preiser [5] analyzed a group of polyps with features similar to HPPs and adenomas and concluded that most of these cases were actually adenomas with a serrated morphology, which led to the term 'serrated adenoma'. These serrated polyps have a sawtooth pattern of crypt infolding as a distinct histological feature (Figure 1).
In the late 1970s, reports of colon cancer developing in patients with numerous colonic HPPs began to come to light. This characteristic condition was later termed hyperplastic polyposis syndrome (HPS) [2-4,6-8]. It is now accepted that patients with HPS are at increased risk for colorectal cancer $[6,8]$. An analysis of polyps from patients with HPS by Torlakovic et al. [9] found that the morphology of these polyps differed from the usual small HPPs that are typically seen in the left colon. These lesions seen in patients with HPS were morphologically distinct and included serration and architectural distortion, and some had areas of cytologic dysplasia. Thus, the term sessile serrated adenoma (SSA) was coined in 2003 to distinguish these polyps from traditional serrated adenomas (TSAs) [9]. SSAs are typically characterized histologically by the extension of the serrations to the crypt base and dilated L or inverted T-shaped crypts [10]. Today, the term serrated polyp has become an umbrella term that encompasses HPPs, TSAs, SSAs, and mixed polyps (mixed polyps consist of SSAs with focal areas of 
Figure I. Histology of a serrated polyp

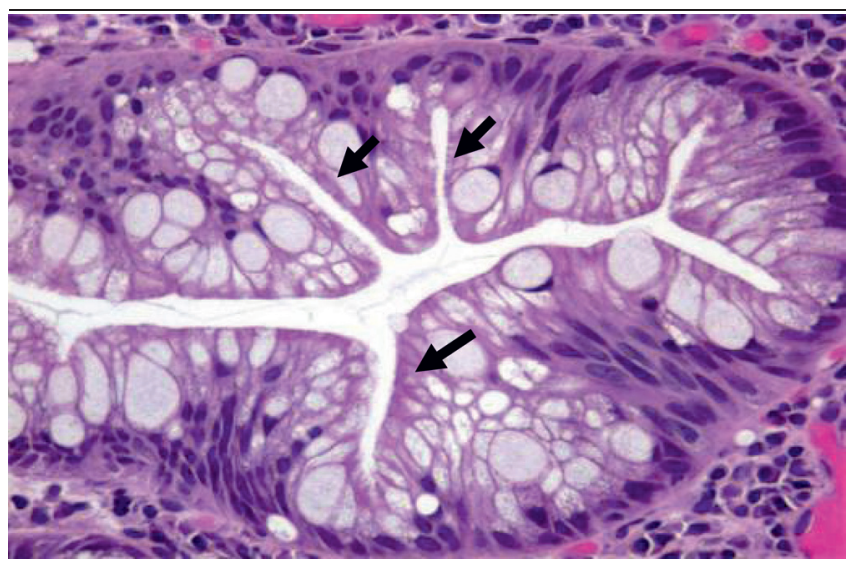

Arrows highlight the sawtooth configuration.

classical dysplasia; see Figure 2). It has been postulated that, under certain circumstances, a serrated polyp can become cancerous when an HPP evolves into an SSA, then to a mixed polyp, and finally to a serrated colon cancer, as discussed below $[7,11,12]$. In addition, studies have suggested that the presence of a large serrated polyp is predictive of synchronous advanced colorectal neoplasia [13].

Accumulating evidence indicates that SSAs may be a precursor lesion for sporadic colon cancers with high-

Figure 2. Types of serrated polyp

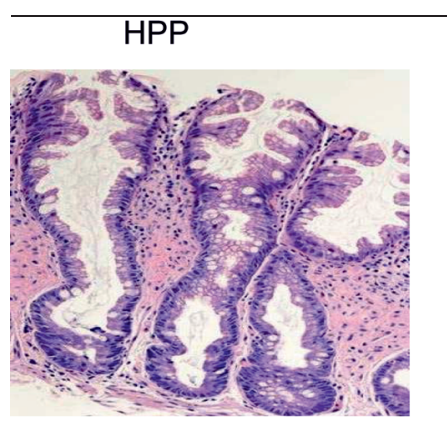

TSA
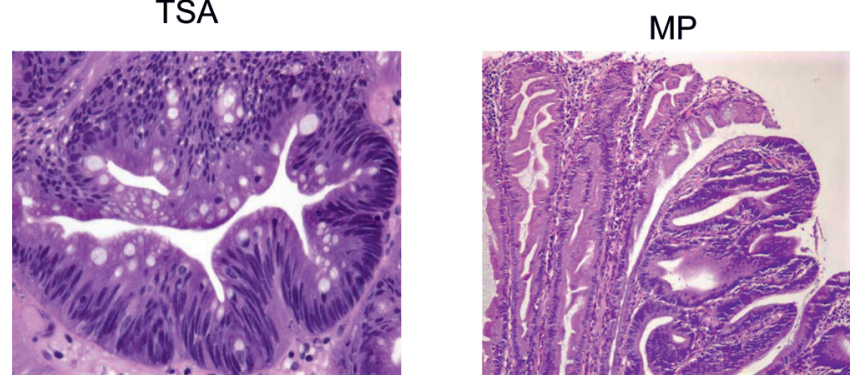

HPP, hyperplastic polyp; MP, mixed polyp; SSA, sessile serrated adenoma; TSA, traditional serrated adenoma. frequency microsatellite instability (MSI-H) $[11,14,15]$. As such, both are more common in the proximal colon and are found in women more often than men [16]. In a histologic analysis of lesions previously described as HPPs and removed at sites where MSI-H cancers were later diagnosed, such polyps were later reclassified as SSAs [17]. While the majority ( $80-85 \%)$ of colon cancers arise from adenomatous polyps through a classical pathway characterized by chromosomal instability, a subset (15-20\%) develop via an alternative pathway characterized by MSI-H that is due to deficient DNA mismatch repair (MMR) [18-20]. In sporadic cases, MSI-H is due to the inactivation of the MMR gene MLH1 by DNA hypermethylation, whereas in Lynch Syndrome (also called hereditary nonpolyposis colorectal cancer), MSI-H is due to a germline mutation in an MMR gene [19-21]. SSAs share common molecular features with sporadic MSI-H cancers, including a high rate of activating mutations in the BRAF gene and hypermethylation of multiple genes, a characteristic termed the ' $\mathrm{CpG}$ island methylator phenotype' (CIMP) [14,15]. BRAF mutations are not found in MSI-H colon cancers from patients with Lynch Syndrome, and therefore can be used to distinguish sporadic tumors from germline MSI-H tumors. Mutations in BRAF have been shown to be mutually exclusive with KRAS mutations $[14,17,22,23]$.

\section{Recent advances}

There are distinct histological and genetic differences between serrated polyps and conventional adenomas (Figure 1 and Figure 3). Histologically and by definition, all conventional adenomas show epithelial dysplasia, whereas SSAs often display cytological atypia or dysplasia but not the classical dysplastic morphology of conventional adenomas [9-11]. TSAs and mixed polyps

Figure 3. A conventional colonic adenoma showing dysplastic epithelia

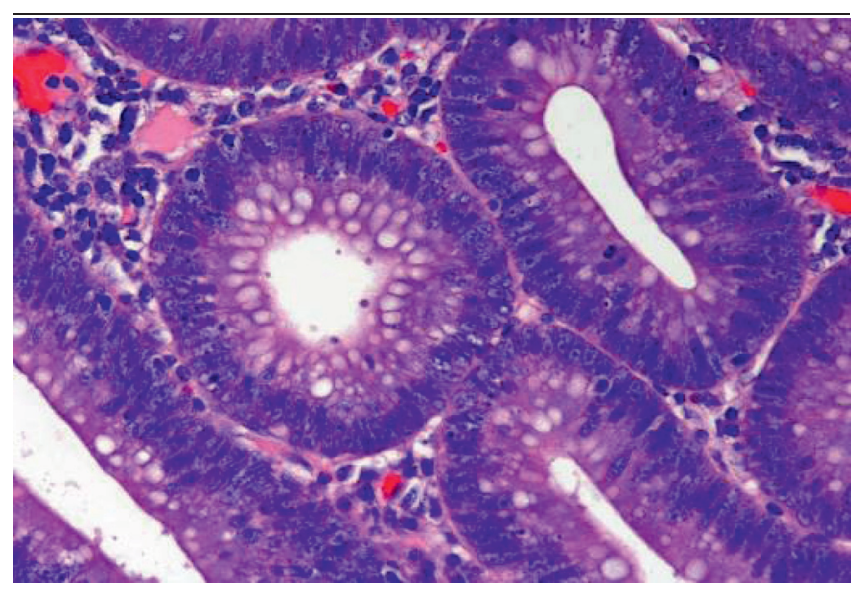


also show classical epithelial dysplasia, but can be differentiated from conventional adenomas by their histology [10,11]. In recent years, there has been a heightened interest in the serrated adenoma pathway, but the lack of uniform terminology and histological interobserver agreement has hampered accurate estimates of the frequency of serrated polyps [10]. Chromoendoscopy has been shown to enhance mucosal detail and lesion detection $[24,25]$. In two recent studies, one of which utilized chromoendoscopy, the frequency of serrated polyps was estimated to be as follows: HPPs were seen in $\sim 30 \%$ of patients, SSAs in $4-9 \%$, TSAs in $\sim 0.7 \%$, and mixed polyps in $0.7-1.7 \%[16,26]$.

Colonoscopy with polypectomy has been shown to decrease the incidence and mortality associated with colorectal cancer $[27,28]$. Interestingly, studies have shown that interval colon cancers, defined as colon cancers that develop within 5 years of a colonoscopy, are more likely to be located in the right colon and to show MSI-H $[10,11,22]$. SSAs may be the precursor lesions for MSI-H colon cancers, which account for approximately $15 \%$ of new colon cancer diagnoses $[11,14,15]$. This link is strongest at the molecular level, given the presence of CIMP and mutations in BRAF in both SSAs and established MSI-H colon cancers. In a large retrospective study conducted in Canada, Baxter et al. [29] found that colonoscopy decreases mortality from left-sided but not right-sided colon cancers. While the explanation for the reduced effectiveness of colonoscopy for detecting rightsided lesions remains unclear, it is tempting to speculate that SSAs may contribute to missed lesions as they are mostly sessile, generally right-sided, and appear to be precursors of MSI-H colon cancers $[14,17,22,23,30]$. However, to date, there is limited data on the natural history and rate of progression of serrated adenomas to colon cancer. Until more is known about their natural history, colon cancer surveillance guidelines remain the same for patients found to have serrated adenomas as those with conventional adenomas. The crucial factors that guide the interval and frequency of surveillance colonoscopy are the size and number of polyps and the degree of mucosal dysplasia [31].

\section{Implications for clinical practice}

The discovery that serrated polyps are a distinct histological entity and that a subset are associated with a risk of progression to colon cancer has lead to a paradigm shift in our understanding of colon polyps. Serrated polyps include hyperplastic lesions with cytological dysplasia distinct from that associated with conventional colonic adenomas, and are referred to as serrated adenomas. Among the more important findings is that SSAs may be the precursor lesions for MSI-H colon cancers. Furthermore, there is evidence that serrated polyps are more likely to be missed during colonoscopy $[10,11,22]$. As a result, colonoscopic follow-ups for serrated adenomas should be the same as for conventional adenomatous polyps. Future challenges include enhancing polyp recognition and improving uniformity in the pathological interpretation of serrated polyps. Another vital challenge will be to improve detection and complete removal of serrated polyps during endoscopy. Meeting these challenges while maintaining vigilant colonoscopic surveillance are essential steps toward colon cancer prevention.

\section{Abbreviations}

CIMP, CpG island methylator phenotype; HPP, hyperplastic polyp; HPS, hyperplastic polyposis syndrome; MMR, mismatch repair; MSI-H, high-frequency microsatellite instability; SSA, sessile serrated adenoma; TSA, traditional serrated adenoma.

\section{Competing interests}

The authors declare that they have no competing interests.

\section{Acknowledgements}

Photographs courtesy of Thomas Smyrk, MD.

\section{References}

I. Jemal A, Siegel R, Xu J, Ward E: Cancer Statistics, 20 I 0. CA Cancer J Clin 2010, 60:277-300.

2. Bengoechea $O$, Martinez-Penuela JM, Larrinaga B, Valerdi J, Borda F: Hyperplastic polyposis of the colorectum and adenocarcinoma in a 24-year-old man. Am J Surg Pathol 1987, I I:323-7.

3. Cooper HS, Patchefsky AS, Marks G: Adenomatous and carcinomatous changes within hyperplastic colonic epithelium. Dis Colon Rectum 1979, 22:152-6.

4. Whittle TS, Jr, Varner W, Brown FM: Giant hyperplastic polyp of the colon simulating adenocarcinoma. Am J Gastroenterol I978, 69: 105-7.

5. Longacre TA, Fenoglio-Preiser CM: Mixed hyperplastic adenomatous polyps/serrated adenomas. A distinct form of colorectal neoplasia. Am J Surg Pathol 1990, 14:524-37.

6. Leggett BA, Devereaux B, Biden K, Searle J, Young J, Jass J: Hyperplastic polyposis: association with colorectal cancer. Am J Surg Pathol 200I, 25:177-84.

7. O'Brien MJ: Hyperplastic and serrated polyps of the colorectum. Gastroenterol Clin North Am 2007, 36:947-68.

8. Place RJ, Simmang CL: Hyperplastic-adenomatous polyposis syndrome. J Am Coll Surg 1999, I 88:503-7.

9. Torlakovic E, Skovlund E, Snover DC, Torlakovic G, Nesland JM: Morphologic reappraisal of serrated colorectal polyps. Am J Surg Pathol 2003, 27:65-8I.

10. Leggett B, Whitehall V: Role of the serrated pathway in colorectal cancer pathogenesis. Gastroenterology 2010, I38:2088-100.

II. Groff RJ, Nash R, Ahnen DJ: Significance of serrated polyps of the colon. Curr Gastroenterol Rep 2008, 10:490-8.

12. Jass JR, Smith M: Sialic acid and epithelial differentiation in colorectal polyps and cancer-a morphological, mucin and lectin histochemical study. Pathology 1992, 24:233-42. 
13. Li D, Jin C, McCulloch C, Kakar S, Berger BM, Imperiale TF, Terdiman JP: Association of large serrated polyps with synchronous advanced colorectal neoplasia. Am J Gastroenterol 2009, 104:695-702.

14. Kambara T, Simms LA, Whitehall VL, Spring KJ, Wynter CV, Walsh MD, Barker MA, Arnold S, McGivern A, Matsubara N, Tanaka N, Higuchi T, Young J, Jass JR, Leggett BA: BRAF mutation is associated with DNA methylation in serrated polyps and cancers of the colorectum. Gut 2004, 53: I I37-44.

15. O'Brien MJ, Yang S, Mack C, Xu H, Huang CS, Mulcahy E, Amorosino M, Farraye FA: Comparison of microsatellite instability, CpG island methylation phenotype, BRAF and KRAS status in serrated polyps and traditional adenomas indicates separate pathways to distinct colorectal carcinoma end points. Am J Surg Pathol 2006, 30:|49|-50I.

16. Spring KJ, Zhao ZZ, Karamatic R, Walsh MD, Whitehall VL, Pike T, Simms LA, Young J, James M, Montgomery GW, Appleyard M, Hewett D, Togashi K, Jass JR, Leggett BA: High prevalence of sessile serrated adenomas with BRAF mutations: a prospective study of patients undergoing colonoscopy. Gastroenterology 2006, I 3 I:1400-7.

17. Goldstein NS: Serrated pathway and APC (conventional)-type colorectal polyps: molecular-morphologic correlations, genetic pathways, and implications for classification. Am J Clin Pathol 2006, I 25: | 46-53.

18. Vogelstein B, Fearon ER, Hamilton SR, Kern SE, Preisinger AC, Leppert M, Nakamura Y, White R, Smits AM, Bos JL: Genetic alterations during colorectal-tumor development. $N$ Engl J Med 1988, 319:525-32.

19. Abdel-Rahman WM, Peltomaki P: Molecular basis and diagnostics of hereditary colorectal cancers. Ann Med 2004, 36:379-88.

20. Lynch HT, de la Chapelle A: Hereditary colorectal cancer. N Engl J Med 2003, 348:919-32.

21. Abdel-Rahman WM, Peltomaki P: Lynch syndrome and related familial colorectal cancers. Crit Rev Oncog 2008, 14:1-22; discussion 23-3I.

22. Arain MA, Sawhney M, Sheikh S, Anway R, Thyagarajan B, Bond JH, Shaukat A: CIMP status of interval colon cancers: another piece to the puzzle. Am J Gastroenterol, 105: I 189-95.

23. Kim YH, Kakar S, Cun L, Deng G, Kim YS: Distinct CpG island methylation profiles and BRAF mutation status in serrated and adenomatous colorectal polyps. Int J Cancer 2008 1 23:2587-93

24. Lee JH, Kim JW, Cho YK, Sohn Cl, Jeon WK, Kim BI, Cho EY: Detection of colorectal adenomas by routine chromoendoscopy with indigocarmine. Am J Gastroenterol 2003, 98: 1284-8.

25. Trecca A, Gai F, Di Lorenzo GP, Hreniuc H, Pasciuto A, Antonellis F, Sperone M: [Conventional colonoscopy versus chromoendoscopy and magnifying endoscopy for the diagnosis of colorectal lesions: a comparative prospective study in 995 patients]. Chir Ital 2004, 56:31-6.

26. Carr NJ, Mahajan H, Tan KL, Hawkins NJ, Ward RL: Serrated and non-serrated polyps of the colorectum: their prevalence in an unselected case series and correlation of BRAF mutation analysis with the diagnosis of sessile serrated adenoma. J Clin Pathol 2009, 62:516-8.

27. Pignone M, Rich M, Teutsch SM, Berg AO, Lohr KN: Screening for colorectal cancer in adults at average risk: a summary of the evidence for the U.S. Preventive Services Task Force. Ann Intern Med 2002, I37:| 32-4I.

28. Winawer SJ, Zauber AG, Fletcher RH, Stillman JS, O’Brien MJ, Levin B, Smith RA, Lieberman DA, Burt RW, Levin TR, Bond JH, Brooks D, Byers T, Hyman N, Kirk L, Thorson A, Simmang C, Johnson D, Rex DK; US Multi-Society Task Force on Colorectal Cancer; American Cancer Society: Guidelines for colonoscopy surveillance after polypectomy: a consensus update by the US MultiSociety Task Force on Colorectal Cancer and the American Cancer Society. Gastroenterology 2006, I30:1872-85.

29. Baxter NN, Goldwasser MA, Paszat LF, Saskin R, Urbach DR, Rabeneck L: Association of colonoscopy and death from colorectal cancer. Ann Intern Med 2009, I 50: |-8.

FI000 Factor 8

Evaluated by Brenda Hoffman 26 Mar 2009

30. Ward RL, Cheong K, Ku SL, Meagher A, O'Connor T, Hawkins NJ: Adverse prognostic effect of methylation in colorectal cancer is reversed by microsatellite instability. J Clin Oncol 2003, 2 I:3729-36.

31. East JE, Saunders BP, Jass JR: Sporadic and syndromic hyperplastic polyps and serrated adenomas of the colon: classification, molecular genetics, natural history, and clinical management. Gastroenterol Clin North Am 2008, 37:25-46. 